\title{
Compact Ultra-Wide Band MIMO Antenna System for Lower 5G Bands
}

\author{
Haitham AL-Saif $\mathbb{D},{ }^{1}$ Muhammad Usman $(\mathbb{D})^{1}$ \\ Muhammad Tajammal Chughtai, ${ }^{1}$ and Jamal Nasir ${ }^{2}{ }^{2}$ \\ ${ }^{1}$ Electrical Engineering Department, College of Engineering, University of Hail, Saudi Arabia \\ ${ }^{2}$ Department of Electrical Engineering, COMSATS Institute of Information Technology, Abbottabad, KPK, Pakistan
}

Correspondence should be addressed to Muhammad Usman; m.usman@uoh.edu.sa

Received 1 February 2018; Revised 6 April 2018; Accepted 6 May 2018; Published 4 June 2018

Academic Editor: Hassan T. Chattha

Copyright (c) 2018 Haitham AL-Saif et al. This is an open access article distributed under the Creative Commons Attribution License, which permits unrestricted use, distribution, and reproduction in any medium, provided the original work is properly cited.

\begin{abstract}
This paper presents a novel compact $2 \times 2$ planar MIMO antenna system with ultra-wide band capability. Antenna system is specifically designed to target lower 5 th generation operating bands ranging from $2 \mathrm{GHz}$ to $12 \mathrm{GHz}$. This band also covers the IEEE $802.11 \mathrm{a} / \mathrm{b} / \mathrm{g} / \mathrm{n} / \mathrm{ac}$. The antenna array geometry has been simulated using CST MWS. The design is extremely miniaturized with total structure size of $13 \times 25 \times 0.254 \mathrm{~mm}^{3}$. The simulated and measured results have been presented. Measured and simulated return loss values for designed antenna are less than $-10 \mathrm{~dB}$ over the operating band and lowest values of $-35 \mathrm{~dB}$ and $-32.5 \mathrm{~dB}$ can been seen at $5.2 \mathrm{GHz}$ and $9.2 \mathrm{GHz}$, respectively, whereas at the center frequency the return loss is $-25.2 \mathrm{~dB}$. The mutual coupling between both elements is less than $-20 \mathrm{~dB}$ over the transmission bandwidth. Simulated and measured radiation patterns in $\mathrm{E}$ and $\mathrm{H}$ planes at center frequency show nearly isotropic far fields. The maximum gain is measured as $4.8 \mathrm{~dB}$. Promising results of Envelope Correlation Coefficient and gain diversity of the design have been achieved. Simulated and measured results are found in good agreement. The fractional bandwidth of antenna is measured as $143.2 \%$ which satisfies its ultra-wide band response.
\end{abstract}

\section{Introduction}

In the coming years, the global mobile data traffic is likely to be projected by $45 \%$; this means a ten times increase between the years 2016 and 2022 [1]. This massive increase is mainly due to mobile video streaming and implementation of Internet of Things (IoT). This will result in approximately 18 billion IoT out of total 29 billion devices [2]. Due to this reason, the future 5th generation networks would need to overcome the demand of wider spectrum in high frequency range. The key constraint to implement and deploy $5 \mathrm{G}$ networks before 2020 is the availability of frequency spectrum; hence both the higher and lower frequency bands are needed for 5G.

Lower 5G bands are ideal for early deployment, due to their advantageous properties including wave propagation and available bandwidth. The main spectrum bands between $2 \mathrm{GHz}$ and $6 \mathrm{GHz}$ are in the ranges from $3.3 \mathrm{GHz}$ to $4.2 \mathrm{GHz}$ and from $4.4 \mathrm{GHz}$ to $4.990 \mathrm{GHz}$. These bands are presently being considered for initial trials of $5 \mathrm{G}$ networks in a number of countries. Table 1 illustrates the operative regions and their respective lower $5 \mathrm{G}$ bands [3].

In order to meet this challenge and according to the current demands, a novel ultra-wide band (UWB) $2 \times 2$ Multiple Input Multiple Output (MIMO) antenna system has been designed and simulated. This antenna system covers the frequency band ranging from $2 \mathrm{GHz}$ to $12 \mathrm{GHz}$, which covers all the lower $5 \mathrm{G}$ frequency bands. Its array is an ideal candidate for $5 \mathrm{G}$ enabled, handheld devices including mobile phones and tablets. Furthermore, this band also satisfies operating regulations of the UWB according to Federal Communication Commission (FCC) [4]. Also, the designed antenna covers the IEEE $802.11 \mathrm{a} / \mathrm{b} / \mathrm{g} / \mathrm{n} / \mathrm{ac}$ standards for WiFi operation in mobile devices.

By Using the UWB technology, wireless communication devices can transmit over a very wide range of frequency band while consuming lower powers [4]. Also the UWB technology based devices have several other merits including high data-rates, increased bandwidth, and being low in cost 




(a) Front view of MIMO antenna

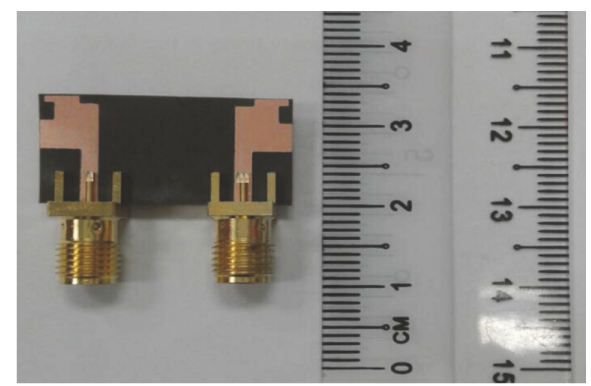

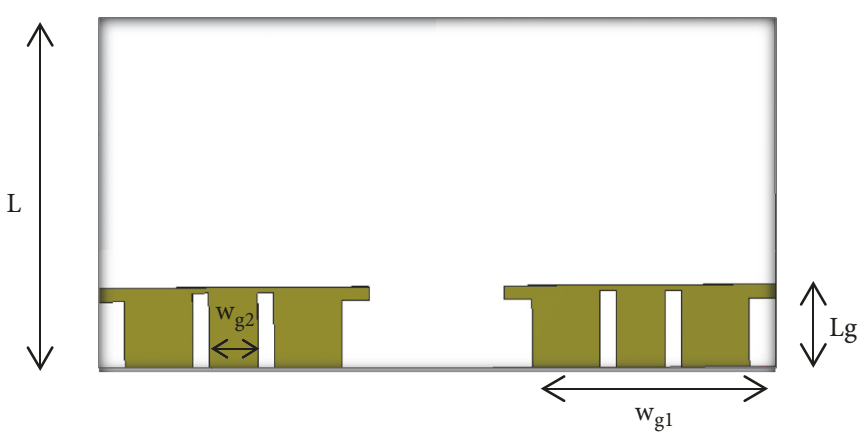

(b) Back view of MIMO antenna

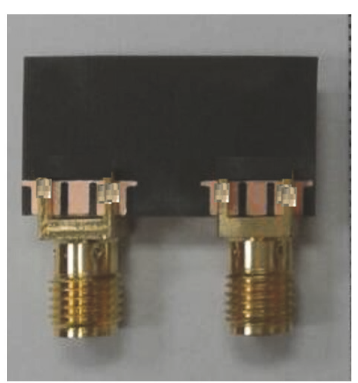

(c) Fabricated antenna

Figure 1

TABLE 1: Regions and lower 5G frequency bands.

\begin{tabular}{lc}
\hline Region & Frequency range $(\mathrm{GHz})$ \\
\hline Europe & $3.4-3.8$ \\
China & $3.4-3.8,4.4-4.5,4.8-4.99$ \\
Japan & $3.6-4.2,4.4-4.9$ \\
Korea & $3.4-3.7$ \\
USA & $3.1-3.55,3.7-4.2$ \\
\hline
\end{tabular}

[5]. In the UWB communication devices, front-end antenna plays very important role. Thus, a lot of work and research [6] has been done to design the UWB antennas for mobile devices. Planar antennas are considered as promising solution for the UWB applications due to their simple design, lower cost, and performance [7].

MIMO antenna systems are vastly implemented in wireless devices to enhance the channel capacity and multipath propagation [8]. In recent times, the UWB and MIMO technologies have been integrated in wireless systems for enhanced performance in terms of high data-rates [9]. The main challenge in designing these kinds of antenna systems are to reduce the mutual coupling between the radiating elements within smaller volumes of small handheld devices. This can be achieved by polarization diversity or by increasing the space between the antennas [8]. Crosspolarized antenna geometries are usually complicated in design, whereas increasing the space between the antennas results in larger volumes [10]. For implementation of the UWB MIMO systems, some good methods are radiation pattern diversity, space diversity, and polarization diversity.
In this paper, space diversity is achieved by using two asymmetric " $F$ " type structures with a very compact fractured ground plane [11].

\section{Antenna Design Methodology and Configuration}

The designed antenna is an extremely compact $2 \times 2 \mathrm{UWB}$ MIMO antenna system. The antenna consists of two asymmetric "F" type structures with a very compact fractured ground plane. The overall volume of the antenna geometry is $25 \times 13 \times 0.254 \mathrm{~mm}^{3}$. The proposed antenna system has been fabricated on Rogers substrate (5880) with relative permittivity, dielectric loss tangent, and height values of 2.2, 0.0009 , and $0.254 \mathrm{~mm}$, respectively. The front and rear views of the designed antenna system are shown in Figures 1(a), $1(\mathrm{~b})$, and $1(\mathrm{c})$.

To start with a single antenna element which has been designed, a detailed parametric study has been done using CST microwave studio. The final values of all geometric variables are presented in Table 2.

The "F" shaped patched monopole design is selected due to its wide band characteristics and enhanced performance in $\mathrm{S}, \mathrm{C}$, and $\mathrm{X}$ bands [12-16]. The overall dimensions of the single $\mathrm{F}$ shaped patch have been optimized to achieve the UWB characteristics. In order to incorporate a $2 \times 2 \mathrm{MIMO}$ antenna array, a second $F$ shaped patch has been reciprocated on the same plane. Both antenna ports are resonated at an input impedance of $50 \Omega$. To reduce the coupling between the two radiating elements, a distance of $13.9 \mathrm{~mm}$ has been carefully 
TABLE 2: Antenna design geometric variables.

\begin{tabular}{|c|c|c|c|c|c|c|c|c|c|c|c|c|c|c|c|}
\hline Variables & $L$ & $W$ & $H$ & $W_{f}$ & $L_{f}$ & $W_{1}$ & $W_{2}$ & $W_{3}$ & $W_{g 1}$ & $W_{g 2}$ & $L_{g}$ & $L_{1}$ & $L_{2}$ & $L_{s}$ & $W_{s}$ \\
\hline Dimensions in $\mathrm{mm}$ & 13 & 25 & 0.9 & 1.6 & 6.5 & 5.9 & 4.9 & 1.6 & 10 & 1.8 & 3 & 3.5 & 2 & 3 & 0.6 \\
\hline
\end{tabular}

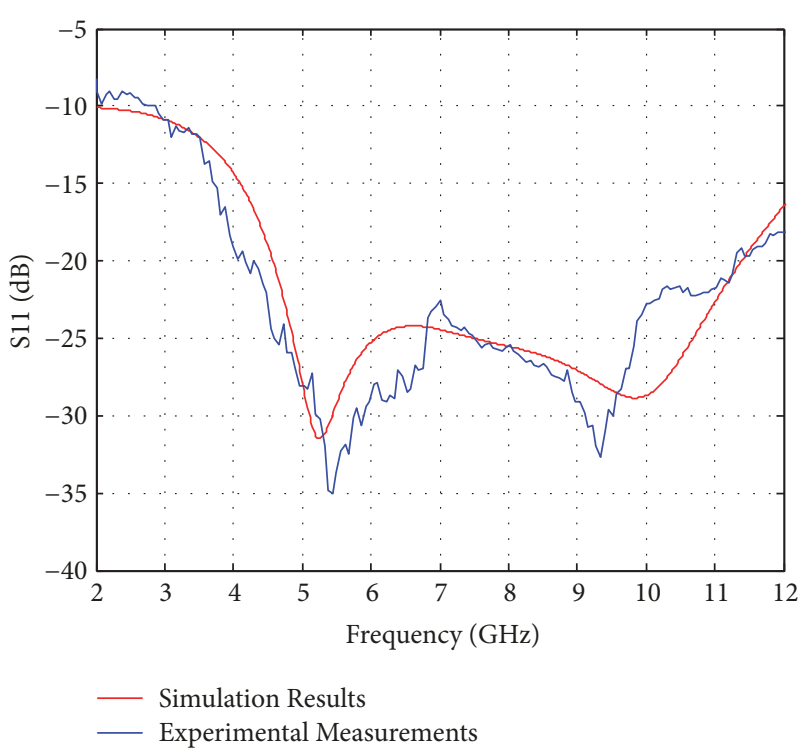

FIGURE 2: Simulated and measured reflection coefficients $\left(S_{11}, S_{22}\right)$.

selected, where this value corresponds to a half wavelength at the upper frequency of operation. Furthermore, compact fractured ground plane has been incorporated; the size of the ground plane is very compact having dimensions of $10 \times$ $3 \mathrm{~mm}^{2}$. Fractured ground plane helped in achieving the target port impedance at the resonant frequency band.

\section{Results and Discussion}

The presented ultra-wide band $2 \times 2$ coplanar MIMO array antenna comprised two "F" shaped monopoles. The geometry has been further modified to achieve the targeted bandwidth and reflection coefficient for $50 \Omega$ input port impedance. Both antenna elements exhibited identical reflection coefficients $\left(S_{11}, S_{22}\right)$. The simulated and measured reflection coefficients are shown in Figure 2.

As it can be seen from Figure 2, the antenna geometry is resonant at wide range of frequency band starting from $2 \mathrm{GHz}$ to $12 \mathrm{GHz}$. The lowest values of refection coefficients are observed as $-35 \mathrm{~dB}$ and $-32.5 \mathrm{~dB}$ at $5.2 \mathrm{GHz}$ and $9.2 \mathrm{GHz}$, respectively. The return loss is well under $-10 \mathrm{~dB}$ for overall band, whereas at center frequency of $8 \mathrm{GHz}$ the return loss has been measured as $-25.2 \mathrm{~dB}$. While designing MIMO antenna systems, the main effort achieved lower value of transmission coefficient between the ports and this is regarded as a key factor in design. It can be seen in Figure 3 that both monopoles are well decoupled; also the mutual coupling between both elements in operating band is well under $-20 \mathrm{~dB}$. In case of the operation of UWB, usually the

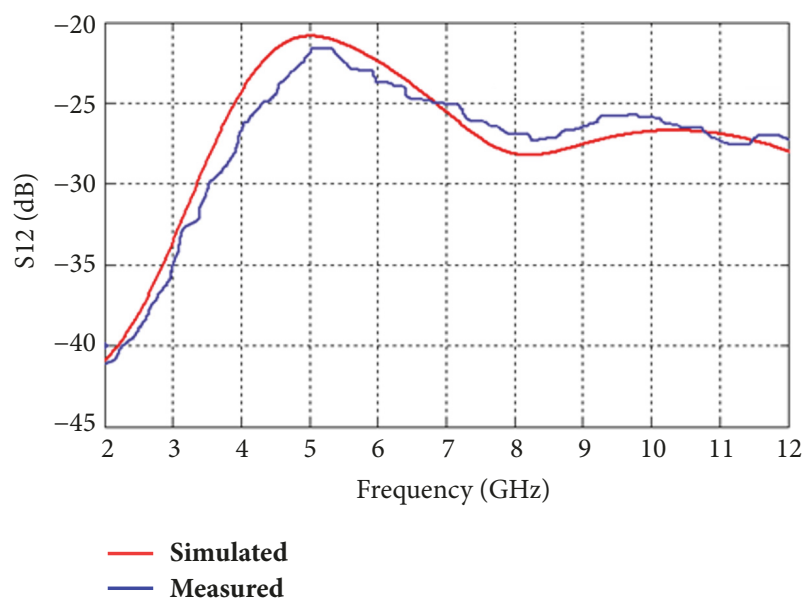

FIGURE 3: Simulated and measured transmission coefficient $\left(S_{12}\right)$.

fractional bandwidth should remain above 50\% [17], whereas for the antenna system under consideration the fractional bandwidth is measured as $143.2 \%$ which satisfies ultra-wide band operation.

The normalized graphs of simulated and measured radiation patterns for the designed antenna system are shown in Figure 4.

For both antenna elements, the radiation patterns are investigated in $\mathrm{E}$ and $\mathrm{H}$ planes at center frequency of $8 \mathrm{GHz}$. The center frequency has been selected to measure the radiation patterns at which the return loss is $-25.2 \mathrm{~dB}$. The measurement has been done by exciting each port at a time, while the other port is connected to a matched load of $50 \Omega$. It can be observed in Figure 4 that both simulated and measured far fields are in agreement to each other. Also, both elements show near omnidirectional pattern. However, as it is a patch antenna, therefore, maximum diversity can be seen along $z$ axis. Furthermore, minor changes can be noticed in measured patterns that are due to the absorption errors inside the anechoic chamber. Still the results are very substantial.

Figure 5 shows the measured overall gain of the designed antenna system over the band of frequencies ranging from 2 to $12 \mathrm{GHz}$. A gain of $2.8 \mathrm{~dB}$ has been observed at center frequency.

The gain diversity $\left(G_{\text {app }}\right)$ is considered as most important parameter in MIMO antenna system. This can be calculated by measuring the Envelope Correlation Coefficient (ECC) between the antenna elements of the MIMO system. There are two mechanisms for calculating the values of gain diversity, either using the $S$-parameters of the antenna elements or using the radiation patterns. In this paper, the gain diversity has been calculated using $S$-parameters of the ports. As an assumption, uniform multipath environment has been 



Element $1, \mathrm{E}$ plane $\left(\mathrm{phi}=90^{\circ}\right)$

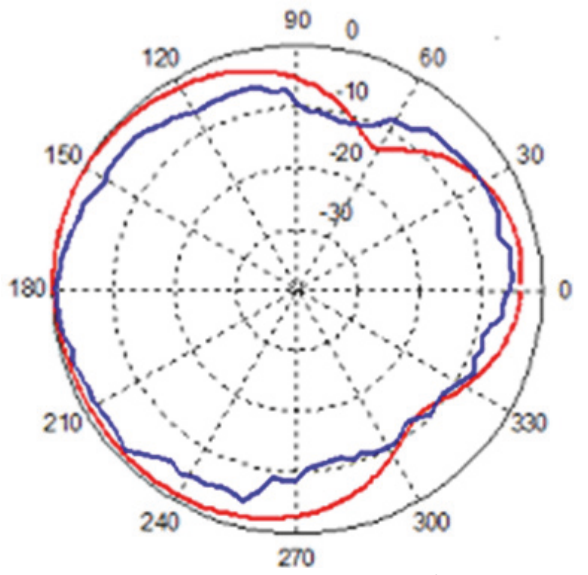

Element $2, \mathrm{E}$ plane $\left(\mathrm{phi}=90^{\circ}\right)$



Element 2, $\mathrm{H}$ plane $\left(\mathrm{phi}=0^{\circ}\right.$ )

— Simulation Results
— Experimental Measurements

— Simulation Results

— Experimental Measurements

FIGURE 4: Simulated and measured radiation patterns.

considered, and the ECC and $G_{\text {app }}$ can be calculated by using the equations given as $[18,19]$.

$$
\begin{aligned}
& \text { ECC, } \rho_{e} \\
& =\frac{\left|S_{11}^{*} S_{12}+S_{21}^{*} S_{22}\right|^{2}}{\left(1-\left(\left|S_{11}\right|^{2}+\left|S_{21}\right|^{2}\right)\right)\left(1-\left(\left|S_{22}\right|^{2}+\left|S_{12}\right|^{2}\right)\right)} \\
& G_{\text {app }}=10 \sqrt{1-|\rho|}, \quad|\rho|=\rho_{e}
\end{aligned}
$$

Figures 6 and 7 represent the measured and simulated results of ECC and gain diversity, respectively. The simulated and measured results for both parameters are very much comparable.

Ideally, the ECC of fully decoupled MIMO antenna system should be zero. As it can be seen from Figure 7, over most of the band the value remains zero. There are few variations present in the measured result at $2 \mathrm{GHz}, 5 \mathrm{GHz}$, and $12 \mathrm{GHz}$; this is due to the reflections which are usually caused by the certain components that are present in the anechoic chamber.

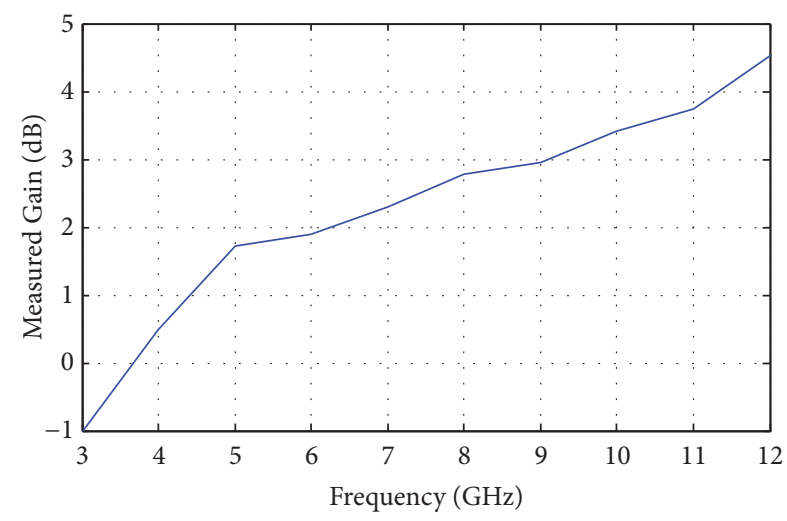

Figure 5: Measured gain of the proposed antenna.

Figure 7 shows the simulated and measured values of gain diversity. As it can be seen from the results, the gain diversity reaches up to $10 \mathrm{~dB}$ over the band of frequencies 


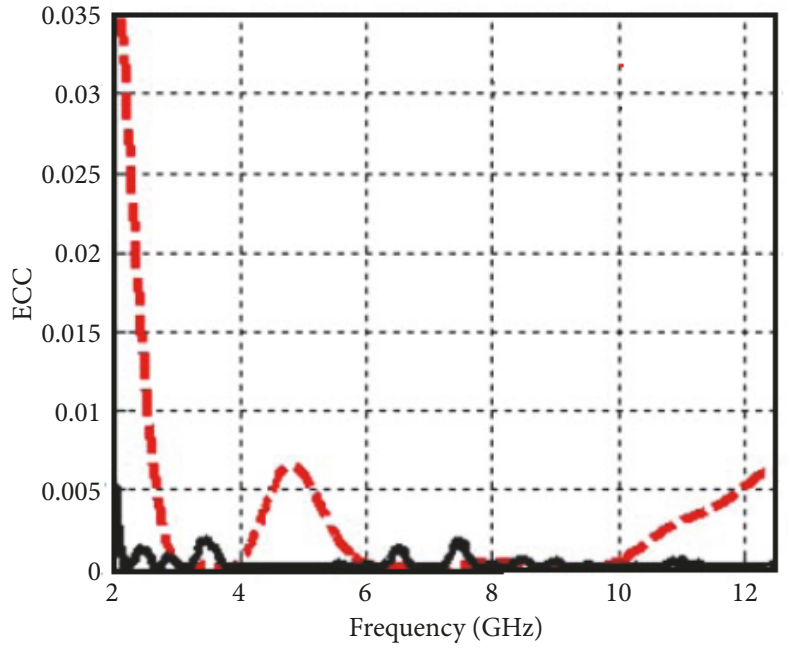

- Measured

- Simulated

Figure 6: Simulated and measured ECC.

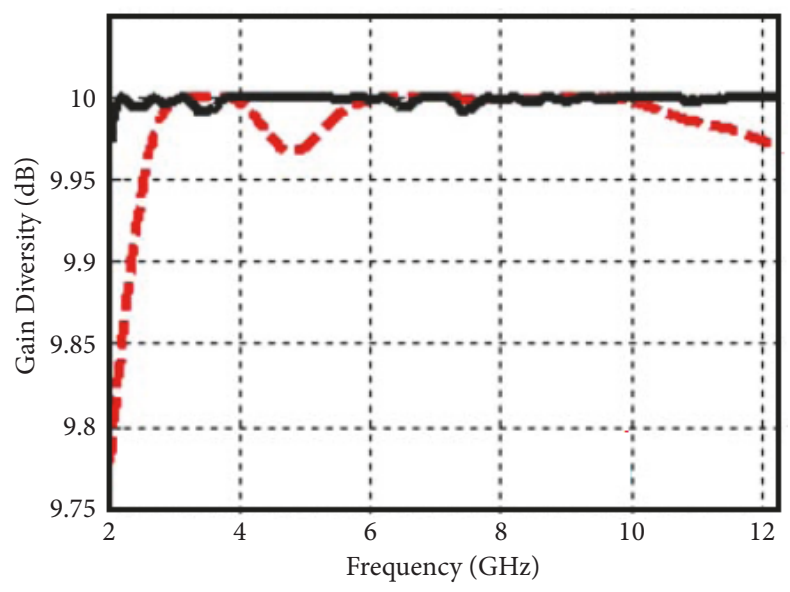

- - Measured

- Simulated

FIGURE 7: Simulated and measured gain diversity.

under consideration. Certain variation can be observed in measured results due to reflections.

A comparison of performance of the proposed antenna with similar antennas available in literature is given in Table 3. This table clearly indicates that the proposed antenna is very compact with high isolation and good MIMO and diversity performance as compared to similar antennas available.

\section{Conclusion}

A novel compact UWB MIMO antenna system has been presented in this paper. The $2 \times 2 \mathrm{MIMO}$ antenna systems consisted of two asymmetric " $F$ " type structures with a very compact fractured ground plane. The presented MIMO antenna system has very compact size; the overall volume is
TABle 3: Performance Comparison of the proposed antenna with previously published work.

\begin{tabular}{lccccc}
\hline Reference & $\begin{array}{c}\text { Size } \\
(\mathrm{mm} 2)\end{array}$ & $\begin{array}{c}\text { Bandwidth } \\
(\mathrm{GHz})\end{array}$ & $\begin{array}{c}\text { Isolation } \\
(\mathrm{dB})\end{array}$ & ECC & $\begin{array}{c}\text { DG } \\
(\mathrm{dB})\end{array}$ \\
\hline$[20]$ & $35 \times 40$ & $3.1-10.6$ & -16 & 0.01 & - \\
{$[21]$} & $27 \times 28$ & $3-10.6$ & -16 & 0.02 & - \\
{$[22]$} & $32 \times 32$ & $3.1-10.6$ & -15 & 0.04 & - \\
{$[23]$} & $50 \times 30$ & $2.5-14.5$ & -20 & 0.04 & 7.4 \\
Proposed work & $13 \times 25$ & $2-12$ & -20 & 0.009 & 9.8 \\
\hline
\end{tabular}

$13 \times 25 \times 0.254 \mathrm{~mm}^{3}$. The distance between two elements of the antenna system is $13.2 \mathrm{~mm}$ and the coupling between both elements over the total transmission bandwidth is less than $-20 \mathrm{~dB}$ with peak minimum values reaching up to $-35 \mathrm{~dB}$. The maximum gain of $4.8 \mathrm{~dB}$ has been observed, whereas the gain at the center frequency was measured as $2.8 \mathrm{~dB}$. Furthermore, the radiation patterns are observed isotropic. Good agreement has been achieved between the results of designed prototype of the MIMO antenna system and its simulated model.

\section{Data Availability}

The data used to support the findings of this study are available from the corresponding author upon request.

\section{Conflicts of Interest}

The authors declare that there are no conflicts of interest regarding the publication of this paper.

\section{Acknowledgments}

This work has been supported by Grant no. BA-1512, awarded by University of Hail, Kingdom of Saudi Arabia.

\section{References}

[1] T. Dateki, H. Seki, and M. Minowa, "From LTE-advanced to 5G: Mobile access system in progress," Fujitsu scientific \& technical journal, vol. 52, no. 2, pp. 97-102, 2016.

[2] W. OBILE, "Ericsson mobility report," ed: Nov, 2016.

[3] G. Association, "5G Spectrum-Public Policy Position," White Paper, Nov 2016.

[4] W. FCC, "DC, Federal Communications Commission revision of Part 15 of the Commissions rules regarding ultra-wideband transmission systems," First Report Order FCC, vol. 2, p. V48, 2002.

[5] F. E. Tubbal, R. Raad, and K.-W. Chin, "A wideband F-shaped patch antenna for S-band CubeSats communications," in Proceedings of the 10th International Conference on Signal Processing and Communication Systems, ICSPCS 2016, aus, December 2016.

[6] Y. Li, B. Yu, H. Shen, L. Zhu, and G. Yang, "An 8-port planar UWB MIMO antenna for future 5G micro wireless access point applications," in Proceedings of the 2017 International Applied Computational Electromagnetics Society Symposium in China, ACES-China 2017, chn, August 2017. 
[7] J. Xu, M. Zhao, R. Zhang et al., "A Wideband F-Shaped Microstrip Antenna," IEEE Antennas and Wireless Propagation Letters, vol. 16, pp. 829-832, 2017.

[8] M. Usman, R. A. Abd-Alhameed, and P. S. Excell, "Design considerations of MIMO antennas for mobile phones," in Proceedings of the Progress in Electromagnetics Research Symposium 2008, PIERS 2008 Hangzhou, pp. 718-722, chn, March 2008.

[9] M. Welborn and J. McCorkle, "The importance of fractional bandwidth in ultra-wideband pulse design," IEEE International Conference on Communications, vol. 2, pp. 753-757, 2002.

[10] S. S. Jehangir and M. S. Sharawi, "A Miniaturized UWB Biplanar Yagi-Like MIMO Antenna System," IEEE Antennas and Wireless Propagation Letters, vol. 16, pp. 2320-2323, 2017.

[11] L. Chen, Y.-F. Liu, and P.-C. Wu, "Design of compact asymmetric coplanar strip-fed UWB antenna with dual band-notched characteristics," Progress in Electromagnetics Research Letters, vol. 47, pp. 103-109, 2014.

[12] B. Kul, G. Kirman, P. Ergul, Z. B. Kartal, and T. Imeci, "L, U, T and F-shaped slots in patch antenna," in Proceedings of the 2017 International Applied Computational Electromagnetics Society Symposium - Italy, ACES 2017, ita, March 2017.

[13] R. Ramasamyraja, M. Pandiguru, and V. Arun, "Design of ultra wide band antenna for tactical communication in electronic warfare," in Proceedings of the 3rd International Conference on Communication and Signal Processing, ICCSP 2014, pp. 12561259, ind, April 2014.

[14] A. A. Omar, "Design of ultrawideband coplanar waveguide-fed Koch-fractal triangular antenna," International Journal of $R F$ and Microwave Computer-Aided Engineering, vol. 23, no. 2, pp. 200-207, 2013.

[15] S. Adnan, R. A. Abd-Alhameed, H. I. Hraga, Z. Z. Abidan, M. Usman, and S. M. R. Jones, "Design studies of ultra-wideband microstrip antenna for ultra-wideband communication," in Proceedings of the Loughborough Antennas and Propagation Conference, LAPC 2009, pp. 365-368, gbr, November 2009.

[16] M. Y. Elsalamouny and R. M. Shubair, "Novel design of compact low-profile multi-band microstrip antennas for medical applications," in Proceedings of the Loughborough Antennas and Propagation Conference, LAPC 2015, gbr, November 2015.

[17] Y. Rahayu, T. A. Rahman, R. Ngah, and P. Hall, "Ultra wideband technology and its applications," in Proceedings of the 2008 IFIP International Conference on Wireless and Optical Communications Networks - (WOCN), pp. 1-5, Surabaya, Indonesia, May 2008.

[18] S. Blanch, J. Romeu, and I. Corbella, "Exact representation of antenna system diversity performance from input parameter description," IEEE Electronics Letters, vol. 39, no. 9, pp. 705-707, 2003.

[19] K. Rosengren and P.-S. Kildal, "Radiation efficiency, correlation, diversity gain and capacity of a six-monopole antenna array for a MIMO system: Theory, simulation and measurement in reverberation chamber," pp. 7-16.

[20] S. Zhang, Z. Ying, J. Xiong, and S. He, "Ultrawideband $\mathrm{MIMO} /$ diversity antennas with a tree-like structure to enhance wideband isolation," IEEE Antennas and Wireless Propagation Letters, vol. 8, pp. 1279-1282, 2009.

[21] G. Srivastava and A. Mohan, "Compact dual-polarized UWB diversity antenna," Microwave and Optical Technology Letters, vol. 57, no. 12, pp. 2951-2955, 2015.

[22] J. Ren, W. Hu, Y. Yin, and R. Fan, "Compact printed MIMO antenna for UWB applications," IEEE Antennas and Wireless Propagation Letters, vol. 13, pp. 1517-1520, 2014.
[23] A. Iqbal, O. A. Saraereh, A. W. Ahmad, and S. Bashir, "Mutual Coupling Reduction Using F-Shaped Stubs in UWB-MIMO Antenna," IEEE Access, 2017. 


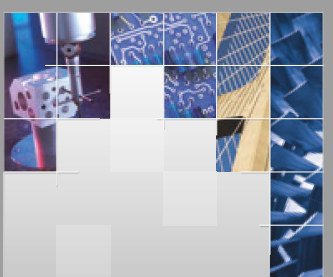

\section{Enfincering}
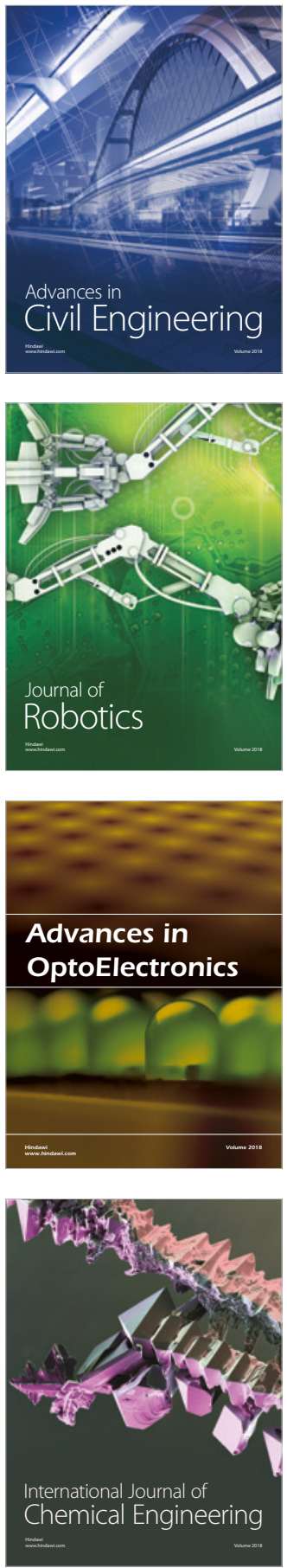

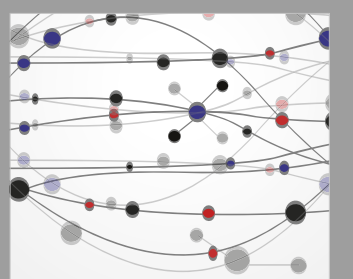

\section{Rotating \\ Machinery}

The Scientific World Journal

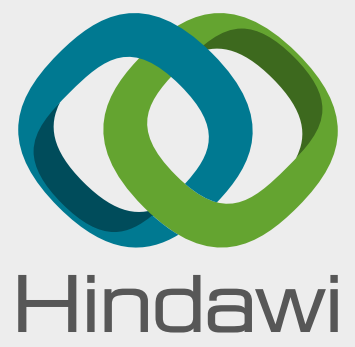

Submit your manuscripts at

www.hindawi.com

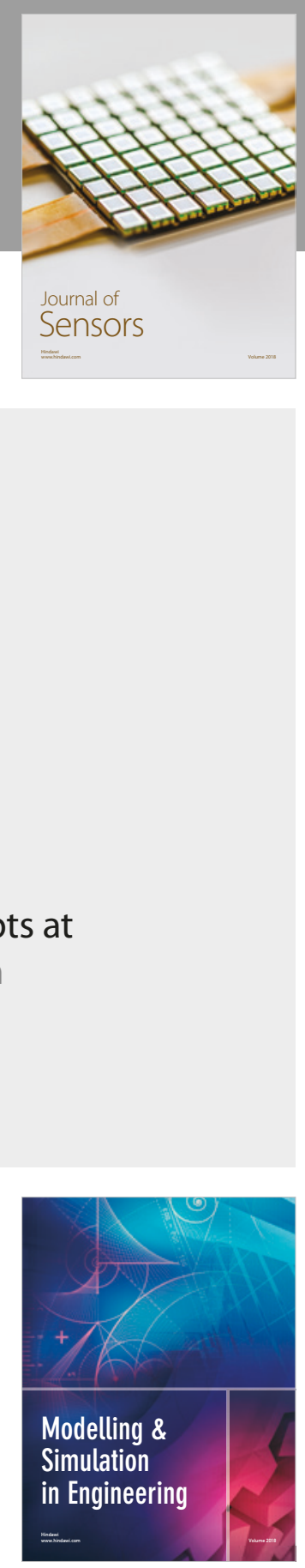

\section{Advances \\ Multimedia}
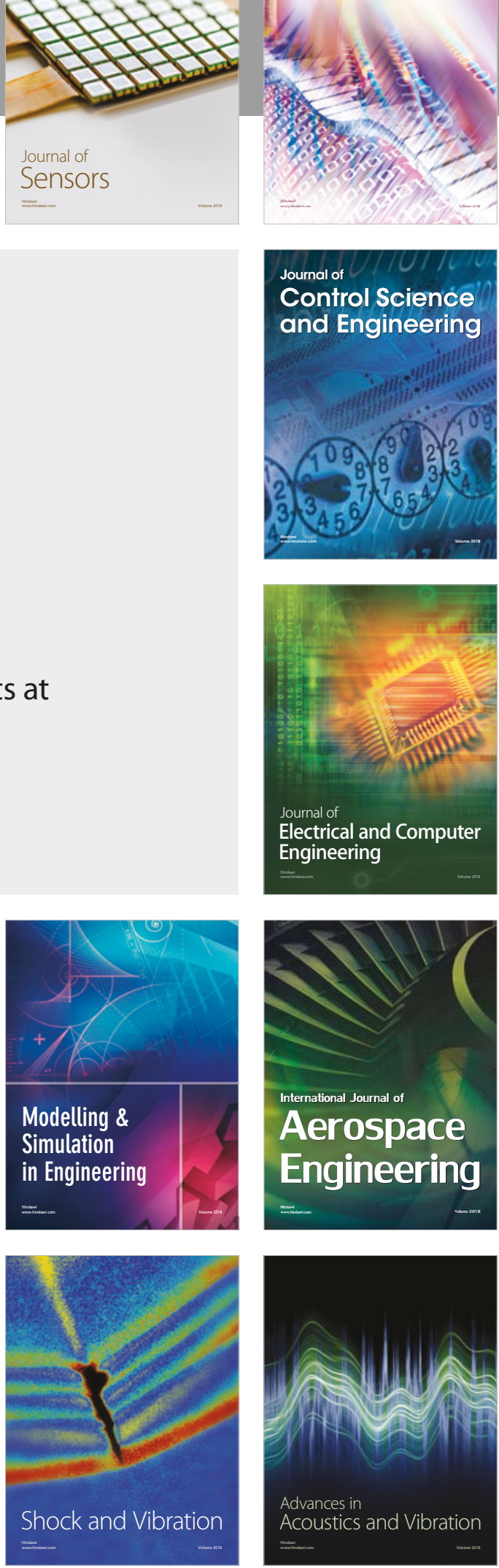